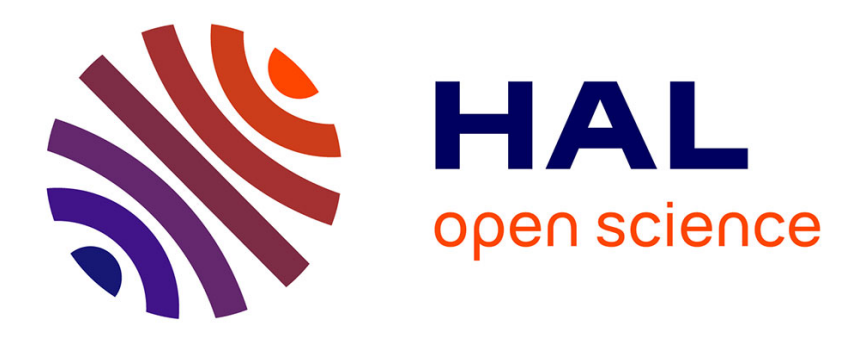

\title{
Working situation health monitoring: Proposal of method and case study
}

Romain Duponnois, Eric Levrat, Ali Siadat, Pascal Lamy

\section{To cite this version:}

Romain Duponnois, Eric Levrat, Ali Siadat, Pascal Lamy. Working situation health monitoring: Proposal of method and case study. 31st European Safety and Reliability Conference, ESREL 2021, Sep 2021, Angers, France. 10.3850/978-981-18-2016-8_403-cd . hal-03351463

\section{HAL Id: hal-03351463 https://hal.science/hal-03351463}

Submitted on 22 Sep 2021

HAL is a multi-disciplinary open access archive for the deposit and dissemination of scientific research documents, whether they are published or not. The documents may come from teaching and research institutions in France or abroad, or from public or private research centers.
L'archive ouverte pluridisciplinaire HAL, est destinée au dépôt et à la diffusion de documents scientifiques de niveau recherche, publiés ou non, émanant des établissements d'enseignement et de recherche français ou étrangers, des laboratoires publics ou privés. 


\title{
Working Situation Health Monitoring: proposal of method and case study
}

\author{
Romain Duponnois \\ Institut national de recherche et de sécurité, Département Ingénierie des équipements de travail, F-54519 Vandouvre-lès-Nancy, \\ France.E-mail: romain.duponnois@inrs.fr
}

Eric Levrat

Université de Lorraine, CNRS, CRAN, F-54000 Nancy, France.E-mail: eric.levrat@univ-lorraine.fr

\author{
Ali Siadat \\ Arts et Métiers Institute of Technology, HESAM, Université de Lorraine, LCFC, F-57000 Metz, France. E-mail: ali-siadat@ensam.eu \\ Pascal Lamy \\ Institut national de recherche et de sécurité, Département Ingénierie des équipements de travail, F-54519 Vandœuvre-lès-Nancy, \\ France.E-mail: pascal.lamy@inrs.fr
}

In a working situation on an automated assembly machine, technical drifts during operation can lead to machine dysfunctions. These dysfunctions may cause the operator supervising the machine to adapt and respond to reduce the effect of these technical drifts on the rest of the working situation. To respond to these dysfunctions the operator may expose him or herself to hazards and thus be in a hazardous situation. (Lamy \& Perrin, 2020) showed the feasibility of identifying this kind of potentially hazardous situation by observing the working situation. Here, we propose a method called Working Situation Health Monitoring (WSHM). The goal of this method is to identify these potentially hazardous situations by analyzing the potential drift of working situations and monitor the advent of potentially hazardous situations using equipment and production data. It consists of three steps: firstly, we model the working situation studied to characterize the nominal working situation; secondly, we analyze cause-and-effect relationships between potential process drifts, potential operator responses and potentially hazardous situations; and thirdly, we construct a health indicator of the working situation based on knowledge of potentially hazardous situations identified in the second step and by equipment data. This paper also presents the application of the method to a case study (an educational automated assembly machine).

Keywords: Occupational safety, Dysfunctional analysis, Work situation, Technical drift, Human-Machine interactions, Human error, Hazardous situation analysis, System modeling.

\section{Introduction}

In France in 2016, nearly ten percent of all work-related accidents occurred on machines (of the 574478 workrelated accidents in France in 2016). Industrial sectors are those most affected, with about a quarter of work-related accidents involving machines. These numbers can be explained by the considerable presence of machines in these sectors (Demasy et al. 2020).

In the same year, accidents on machines caused more than 4,000 permanent disabilities $(12 \%$ of all permanent disabilities over the year) and 3 million days of work stoppage $(7.5 \%$ of all days of work interruption over the year) (Brasseur, Ravallec, and Vaudoux 2019).

To sell a machine on the market of the European Economic Community, all designers and manufacturers must comply with the "essential health and safety requirements" set out in the Machinery Directive 2006/42/EC (CE 2006). This directive is transposed into the French Labor Code by articles R. 4311 and R. 4312). Consequently, confidence is placed in harmonized standards attesting to the conformity of machines with this directive (e.g. ISO12100:2010 (ISO 2010), etc.).

To prevent these accidents, "the solutions to be provided are primarily aimed at intrinsic prevention, in order to eliminate or reduce the risk right from the design stage, by integrating the operating characteristics of the machinery and its maintenance."[2]. The purpose of these solutions is to limit or eliminate the occurrence of hazardous work situations for the operator of work equipment by reducing or eliminating the operator's exposure to a source of hazards.

However, even if risk reduction measures are taken at the design stage, the specificities of the machine's use must also be taken into account. This is done within the framework of the Use Directive 2009/104/EC (CE; 2009) also transposed in the French Labor Code by articles R4321-1 to R4321-5. In this paper, we will look at the impact of the operating context that causes the equipment or the production process to drift. This can lead the machine's operator to react to maintain the performance of 
their machinery. (Pariès 2011; Pariès and Wreathall 2017; Léger 2009).

These drifts can result in modifications of the machine (Polet, Vanderhaegen, and Millot 2009; Vanderhaegen et al. 2011) or of activities carried out by the operator (Pariès 2015; Lamy and Perrin 2020; Hollnagel 2006). These changes are called operator responses to a technical drift (machinery malfunctions, product flow drifts, etc.) and can place the operator in a potentially hazardous situation.

This paper presents an approach for the identification of these potential hazardous situations following an operator response to a technical drift of an automated assembly machine.

This paper is structured as follows:

- Section Two defines the potential hazardous situations following a response by a machine operator to a technical drift.

- Section Three gives an overview of the Working Situation Health Monitoring (WSHM) method proposed and explains its purpose.

- Section Four presents an overview of the first step of the method and a case study.

- Section Five presents an overview of the second step of the method.

- Section Six presents the application of these two steps to a case study.

- Section Seven concludes this article and proposes perspectives for the continuation of this work and the development of the WSHM method, in particular the third step of the WSHM method.

\section{Operator response leading to a hazardous situation}

The link between technical drift, operator response and hazardous situation is defined by Lamy \& Perrin: "When using a machine or automated system, dysfunctions such as the jamming of a part can occur and disturb the normal production process. To solve this dysfunction, the operator may place himself in a hazardous situation." (Lamy and Perrin 2020).

These "operator responses to technical drift" are similar to what is called in ISO12100:2010: "interactions of person(s) with the machine, including the correction of malfunctions" in the part concerning the "human factor" during risk estimation (ISO 2010).

In order to better understand the causal links between the different events leading to a hazardous situation following a response of a machine operator to a technical drift, we first propose to define what is meant by "operator response" and "hazardous situation".

\subsection{Operator response}

During a technical drift, an operator can make the decision to adapt to the drifting situation. (Le Bot 2011). This response contributes to the resilience of the work situation but can also put an operator at risk. An operator's response to a technical drift leading to an accident falls into the category of "human error" and/or "human factors" (Reason 1990; Van Elslande 2000; Chauvin 2010; Vanderhaegen et al. 2011; Larouzée, Guarnieri, and Besnard 2014).
Van Elslande reminds us that "[human] error should not be analyzed as the primary cause of accidents, but rather as the consequence of malfunctions upstream. If man makes a mistake, it is rarely not because he has sought it; it is most often because the external (environmental) as well as internal (human) conditions of his activity did not allow him at a given moment to face the requirements of the [prescribed] task he was confronted with" (Van Elslande 2000).

In this case, the response of an operator to a technical drift is linked to the perception of the situation in which they find themselves (Endsley 2017). An operator supervising the machine(s) as well as the product flow(s) will be able to perceive drifts (Boyd 1995; Endsley and Garland 2000; Hoc 2000; Boy 2015; Duponnois et al. 2019).

The perception of the technical drift is perceived by the operator through the drift of interactions between themselves and the technical component of the working situation (Duponnois et al. 2020).

\subsection{Hazardous situation}

In standard ISO 12100:2010, a hazardous situation is described as the "circumstance in which a person is exposed to at least one hazard" (ISO 2010).

In the same standard, a hazard is described as a "potential source of harm". Harm is described as a "physical injury or damage to health (ISO 2010).

If a person is in a hazardous situation, a hazardous event can lead to harm ("event that can cause harm" (ISO 2010)). Thus, the condition of occurrence of harm can be represented as in the Figure 1.

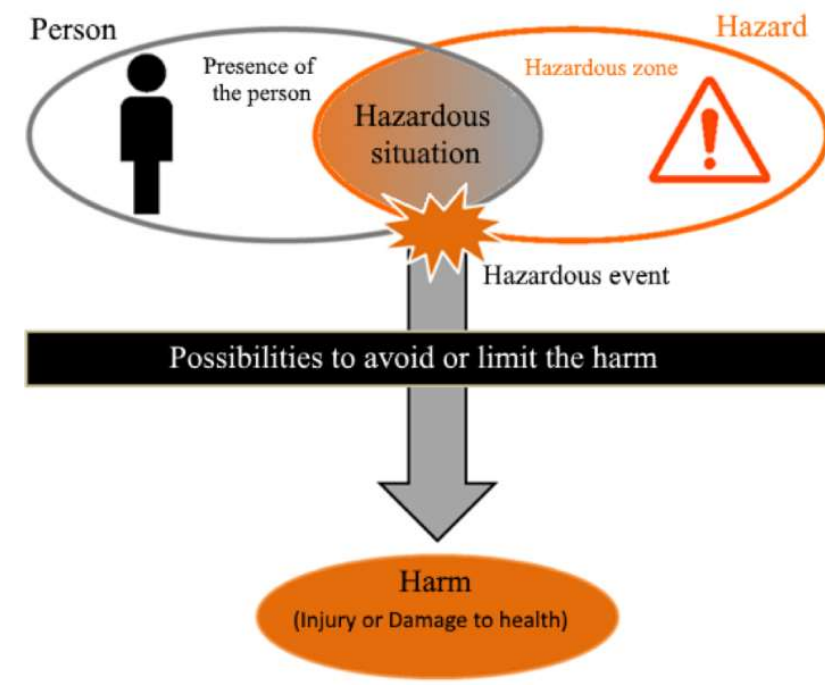

Fig. 1. Condition of occurrence of harm based on ISO/TR 141212 (ISO; 2012).

When a machine operator responds to a technical drift, they can expose themselves to a hazard and thus be in danger (hazardous situation).

To prevent this kind of hazardous situation on automated assembly lines in operation, this paper proposes a method to identify and monitor them: the Working Situation Health Monitoring (WSHM) method. 


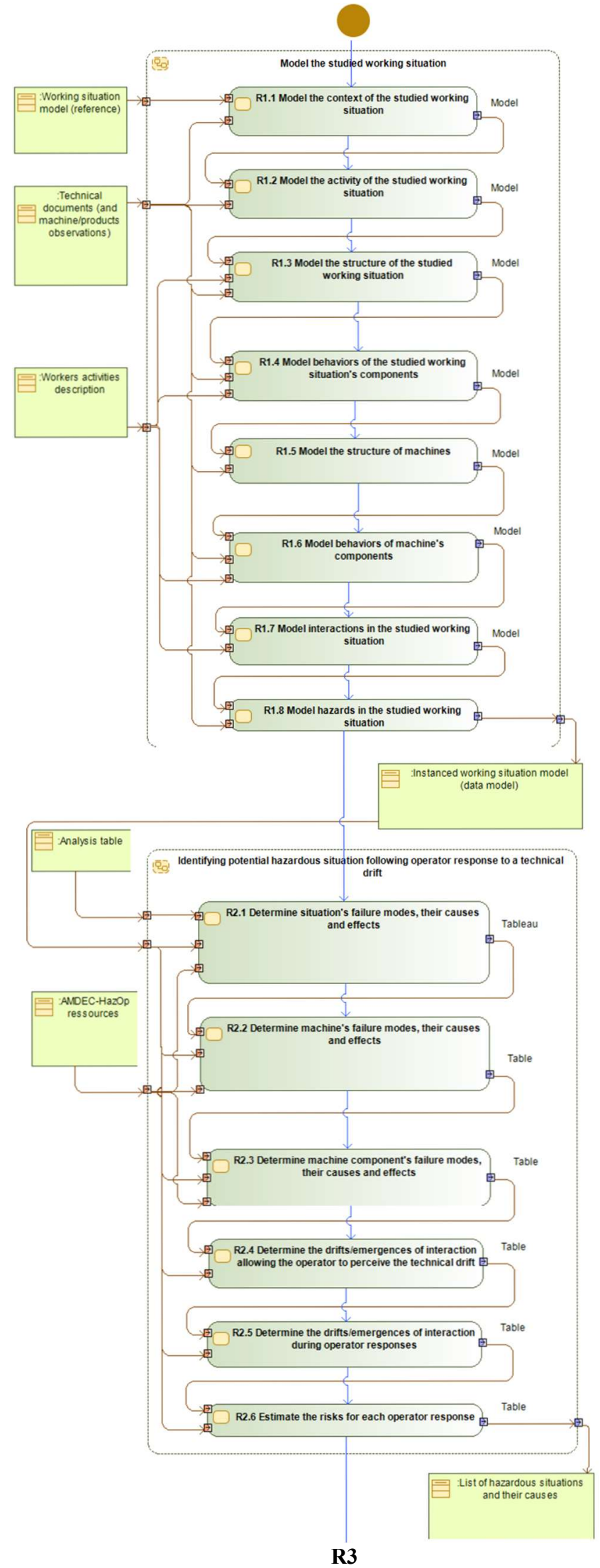

Fig. 2. Activity diagram of the WSHM method proposed.

\section{Proposal of Working Situation Health Monitoring (WSHM) method}

The WSHM method proposes results from the following question: can we monitor an initially safe working situation to anticipate the occurrence of a potential hazardous situation following a response of a machine operator to a technical drift? (Duponnois et al. 2019).

To allow the monitoring of the working situation in an automated and continuous way, this method is based on existing health management tools used to monitor the "health" of a technical component like Prognostic and Health Management described in (Kalgren et al. 2006; Cocheteux 2010).

The goal of the WSHM method is to provide a health indicator of the working situation studied on an automated assembly machine in operation, i.e. the more a hazardous situation is likely to occur, the more the working situation health indicator will be degraded.

To build this health indicator of the working situation, we need to identify a potential hazardous situation following a response by the machine operator to a technical drift. In this part, the dysfunction analysis of the whole situation will be performed. Therefore, in addition to the drift analysis of products (flow and objects) and machines, we propose to analyze the drift and the advent of interactions between operators, machines and products in the working situation.

Prior to the dysfunction analysis, the method will start with the collection of information about the nominal state of the working situation (structure and behavior). Since a working situation is a complex system, we will model it as such. This information collection results in a data model of the working situation studied.

Thus, the WSHM method proposed is divided into three steps:

- First, a modeling step where we model the working situation studied to characterize the nominal working situation (R1);

- Secondly, an identification step where we analyze cause-and-effect relationships between potential process drifts, potential operator responses and potentially hazardous situations (R2);

- Thirdly, an indicator definition step where we construct a health indicator of the working situation based on knowledge of potentially hazardous situations identified in the second step and by equipment data.

The first and second steps will be described in the two following sections. The idea behind the third step will be introduced in the final section.

\section{Modeling the working situation (R1)}

The goal of the first step of the WSHM method is to generate a data model containing information about the working situation studied on machines in the operating phase.

In this first step, we will use the Working situation model presented in (Duponnois et al. 2020) as a reference to model the working situation studied. 
In addition to the reference model, performing this step requires:

- Technical documents: this includes all the documents describing the machines and their components, the raw materials and product descriptions. They can be completed with observations of the working situation studied;

- The description of the machine operator's activity (worker): list of activities assigned to each operator in the working situation.

These documents/observations will be used to study the structure and the behavior of the working situation studied, and identify interactions and hazards in its nominal state (without drift). It should be noted that in a nominal working situation on a machine, the operator cannot be in a hazardous situation even if hazards exist.

A single person (who can be a member of the workgroup of the second step) carries out the first step of the WSHM method.

The result of the first step is an instantiated working situation model of the working situation studied (data model).

\subsection{Sub-steps proposals}

The first step of the WSHM method (R1) is composed of eight sub-steps (R1.1 to R1.8) and represented as an activity diagram (SysML) in Figure 2.

The goal of sub-step R1.1 is to model the working situation studied viewed as a "black box" (the interior of the object is not described in its context). This context is composed of: the description of the working space (physical area in which the work is situated), the physical working environment (parameters like temperature, air pressure, air quality, etc.) and flow of raw materials, products and other objects entering and exiting the working situation.

The goal of sub-step R1.2 is to model the activity of the working situation studied viewed as a "black box". This activity description allows describing which flows (products, information, etc.) enter the situation and which flows leave it.

The goal of sub-step R1.3 is to model the structure of the working situation studied, this time viewed as a "white box" (the interior is described, as opposed to the "black box"). Since a working situation is composed of operators, machines and tools (manual tools for the operator to use), this step consists in modeling each one of them viewed as a "black box". It is noteworthy that since the operator is a human being we will not model them more precisely than a "black box": the goal of this method is not to specifically model humans.

The goal of sub-step R1.4 is to model the behavior/activity of each component of the working situation studied. The activities of the machinery and each operator are modeled. The descriptions of the activities allow describing which flows (products, information, etc.) are exchanged between the components of the working situation.
The goal of sub-step R1.5 is to model the structure of the machines in the working situation studied, this time viewed as a "white box". A machine is composed of its components. This decomposition of the machine into its components is useful for the second step of the WSHM method, where the description of the machine components will be analyzed to better understand the causes of its dysfunctions.

The goal of sub-step R1.6 is to model the behavior/activity of the machine's components. The activities of each machine component are modeled. The descriptions of the activities allow describing which flows (products, information, etc.) are exchanged between the machine's components and between the latter and the other components of the working situation.

The goal of sub-step R1.7 is to model all the interactions between the operator, tools, products and machine components. The way these interactions are modeled is presented in (Duponnois et al. 2020).

The goal of sub-step R1.8 is to model all the hazards and the resulting hazard zone ("any space within and/or around machinery in which a person can be exposed to a hazard" (ISO 2010)). Information on hazards can be found in previous "hazard identifications" performed on the machinery. If none had been carried out on the machinery, a machine risk expert has to perform one to identify the hazards before they can be modeled.

\subsection{Conclusion on the first step of the WSHM method}

At the end of this step, the working situation studied is modeled in the instantiated model of the working situation. This data model includes information about:

- The structure and behavior of the working situation studied, the structure and behavior of machine's/machines' components. This information is used in the second step of the WSHM method to perform a dysfunction analysis of the technical components;

- The description of the interactions between the components of the working situation studied. This information is used in the second step of the WSHM method to analyze the potential perception of a technical drift by an operator and the impact of the operator's response on the rest of the working situation;

- The description of the hazards and the hazard zone present in the working space. This information is used in the second step of the WSHM method to estimate the risk associated with each operator's responses to a technical drift.

Note that the operators are viewed only as "black boxes" in the instantiated model. This choice is justified by the way the method has been thought out: the method takes into account only responses to a technical drift (not other "human factors").

The instantiated model of the working situation (data model) is the principal input of the next step of the WSHM method: "Identifying potential hazardous situations following an operator response to a technical drift". 


\section{Identifying potential hazardous situations following an operator response to a technical drift (R2)}

The goal of this step is to generate a list of potential hazardous situations following an operator response and their technical causes (technical drift).

Current risk analysis methods like Process hazard analysis (MORTUREUX 2002; Desroches 2005), FMECA (IEC 2018) and HAZOP (ROYER 2009; Baybutt 2015) are more focused on the technical part of the working situation to identify hazardous situations. In our case, we want to take into account the whole working situation (actors and interactions between them).

In this second step of the WSHM model, we will use the instantiated model of the working situation (data model) produced during the first step of the WSHM method (presented in section 4).

The second step of the WSHM method is carried out by a workgroup composed of:

- One or more machine experts who know the machine or similar machines;

- One or more machine risk experts to study the risk of each operator response;

- One or more ergonomists to study the potential perception capabilities of the operator;

The goal of this workgroup is to identify potential operator responses following a technical drift and the potential hazardous situation resulting from these responses.

The result of the second step is a table listing all the potential hazardous situations following an operator response to a technical drift where the estimated risks are significant (risks that must be reduced). All the sub-step results are reported in the same table (the "analysis table"). This table is a written record of the analysis and is used throughout the second step of applying the WSHM method.

\subsection{Proposals of sub-steps}

The second step of the WSHM method (R2) is composed of six sub-steps (R2.1 to R2.6) and represented as an activity diagram (SysML) in Figure 2.

The goal of sub-step R2.1 is to perform a dysfunction analysis on the first level of abstraction: the working situation viewed as a "black box". To carry out this step, an AMDEC-HazOp (Reitz et al. 2012) is performed on the information of the working situation activity extracted from the instantiated model of the working situation (data model) to determine:

- Failure modes of the activity of the working situation studied;

- External causes of these failure modes: causes can be drifts of incoming flows of the activity. The "InFlow" drift can be a drift of product or energy flow characteristics; they can also be drifts of product properties. External causes can be drifts of the work environment;

- An Occurrence mark $(\mathrm{O})$ : estimation of the frequency of occurrence of each cause.

- Local effects of these failure modes on the outgoing flows of the activity. The "OutFlow" drift can be a drift of product flow characteristics; they can also be a drift of product properties.

The goal of sub-step R2.2 is to carry out a dysfunction analysis on the second level of abstraction: the working situation viewed as a "white box" with machines and operators (workers) viewed as "black boxes". To carry out this step, an AMDEC-HazOp is performed on the machine and information on operator activities is extracted from the instantiated model of the working situation (data model) to determine:

- The failure modes of each machine activities and each operator's activities in the working situation studied;

- External causes of these failure modes: causes can be drifts of incoming flows of machines or an operator's activities, or drifts of the work environment;

- An Occurrence mark $(\mathrm{O})$ : estimation of the frequency of occurrence of each cause;

- The local effects (drifts) of these failure modes on the outgoing product flows of machine or operator activities;

- Effects on the upper level of abstraction: drifts of outgoing product flows in the activity of the working situation and the failure modes of the working situations, i.e. a failure mode of a machine or an operator activity can be an internal cause of the failure mode of the activity of the working situation.

The goal of sub-step R2.3 is to perform a dysfunction analysis on the third level of abstraction: the machines viewed as "white boxes". To perform this sub-step, the same process as in the previous sub-step is carried out but this time on the information of the activities of the machine's components extracted from the instantiated model of the machine's working situation (data model), i.e. a failure mode of a machine component activity, causes, occurrence rate and effects. The results are reported in a table. After this sub-step, the dysfunction analysis is finished. This analysis results in the identification of potential technical drifts (component/machine failure modes and flow drifts) that can occur during the working situation studied.

The goal of sub-step R2.4 is to identify drift interactions and new interactions in the working situation following a technical drift potentially visible to the operator. For each technical drift (failure mode or causes), the work group carries out a brainstorming session on how this drift can affect interactions within the working situation and especially interactions where the operator is the "sink" (receiver of information, etc. (Bouffaron et al. 2014; Lieber and Morel 2015)). These effects can be drifts in the properties of an existing interaction (drift of an interaction) or occurrences of a new interaction. The group's goal is to identify and characterize the drift and the advent of interactions between an operator and the rest of a working situation.

Existing (nominal) interactions are represented in the instantiated model of the working situation (data model) (Duponnois et al. 2020). An interaction can be seen as a flow; representing an interaction's drift is described as a drift of one of its Time-Space-Shape properties: 
- Time: duration, frequency, start time.

- Space: spatial position/zone of potential interaction.

- Shape: list describing all energies (message or raw power) transmitted from a "source" actor to a "well" actor (Bouffaron et al. 2014; Lieber and Morel 2015)).

Emerging interactions are new interactions that did not occur in the nominal working situation. These interactions are characterized in the same way as nominal interactions (Duponnois et al. 2020). For each drifting or emerging interaction, the potential perception of this drift by the operator is estimated and is also reported in the table, in the Detection column (D-mark).

The goal of sub-step R2.5 is to identify drifting interactions and new interactions in the working situation following a response of an operator to a perceived technical drift. For each perceived technical drift, the work group carries out a brainstorming session to answer these two questions:

- Is the operator responding to the perceived technical drift?

- How can the operator "reasonably" respond to it?

For each potential response identified, the work group identifies the resulting interaction drifts and emerging interactions of these responses (parts of the "reasonably foreseeable behavior" in ISO12100:2010 (ISO 2010)). The description of the interaction drifts and advents are the same as in the previous sub-step (R2.4).

The goal of sub-step R2.6 is to identify operator responses that can potentially lead the operator into a hazardous situation. For each drifting or emerging interaction resulting from an operator's responses to perceived technical drifts, the work group carries out a brainstorming session to estimate the risk, for the operator, related to their responses and the associated interaction drifts and advents. To achieve this analysis, the group uses information about the "hazard zone" and "hazard" presented in the instantiated model of the working situation (data model) and the properties of drifting or new interactions in the table. For each interaction resulting from an operator response, the potential hazard that the operator can be exposed to is estimated and reported in the same table as the previous sub-steps. The severity of the operator's potential injuries for each of the potential hazardous situations identified is estimated and also reported in the table (S-mark in the table). Then a criticality estimation is carried out on each potential hazardous situation identified in this sub-step. This estimation is performed in the same way as in the AMDEC method (IEC 2018) by the mathematical product of $\mathrm{O}, \mathrm{D}$ and $\mathrm{S}$ marking the value present in the table:

- $\quad$ The Occurrence mark $(\mathrm{O})$ : four levels (1 to 4$)$, from less frequent to more frequent,

- The (non)Detection mark (D) : four levels (1 to 4), from more detectable to less detectable,

- The Severity of potential harm for the operator mark (S) : four levels (1 to 4), from less sever to more sever,
The Risk Priority Number (RPN) of each hazardous situation is obtained by using Eq (1).

$$
R P N=O * D * S
$$

With the value of RPN, the work group chooses the hazardous situation that they consider "significant" to monitor and list its causes (technical drifts).

\subsection{Conclusion on the second step of the WSHM method}

At the end of this step, the table constructed during the second step of the WSHM method will be used as a list of all potential hazardous situations following the operator's responses to a technical drift and its causes (technical drift).

For each "significant" hazardous situation that has to be monitored, causal links between the technical drifts and potential hazardous situations are used to define a health indicator of the working situation in the third step of the WSHM method: "Defining a working situation health indicator".

\section{Application of the first and second steps of the WSHM to a case study}

\subsection{Presentation of the case study: Working situation on the SFP}

The case study used in this paper was a working situation taking place on a part of the Système Flexible de Production (SFP) of the Lorrain AIP present on the site of the Science and Technology Faculty of Nancy, France (Figure 2). The SFP platform is an educational platform used to train future automation designers and technicians (AIPL 2021). This platform is also used as a research case study, as in this paper.

The work situation simulated was composed of a member of the work group who played the role of the "operator", a part of the SFP machinery - "SFP machine". The goal of the "SFP situation" was to assemble raw materials "Parts 01" and "Parts 09" into final products "Products 0109".

\subsection{Workgroup composition}

The work group that carried out the application of the WSHM method on the "SFP situation" case study was comprised of the Ph.D. student developing the WSHM method, a system-modeling expert, several industrial machine experts, and several risk analysis experts.

\subsection{Application of the first step of the WSHM method}

To carry out this step, members of the workgroup were given access to technical descriptions of the machine and process in the working situation studied and made several observations on the "SFP machinery" in and out of use.

The "SFP situation" case was modeled using the working situation model (reference model). This model was built as a block definition diagram with the SysML modeling language (OMG 2019) using the Modelio (4.0.1) (Modelio 2021) Software.

During this modeling phase, several Activity diagrams (SysML) were produced to help the identification and characterization of the several activities taking place in the "SFP situation" case. Likewise, for several sequence 
diagrams (SysML) that were produced to help the identification and characterization of interactions between "SFP situation" components.

The resulting data model describes:

- Two raw material flows ("Parts 01 " and "Parts 09");

- One production support flow ("Sled");

- One final product flow ("Product 0109");

- One worker/ operator ("Operator");

- Four activities performed by the "Operator";

- One machine ("SFP machine") composed of 13 machine components. The machine is powered by electrical energy and pneumatic energy.

- 10 activities performed by the components of the "SFP machine";

- 77 interactions between actors (actors are "Operator", "SFP machine" components and products flow);

- 3 types of hazards, 12 hazards and 12 hazard zones.

With all the information in the instantiated model of the working situation, namely the "SFP situation model" (data model), the work group concluded the first step of application to the case study.

\subsection{Application of the second step of the WSHM method}

A dysfunction analysis was carried out using the information extracted from the instantiated model of the working situation, namely the "SFP situation model" (data model). The results were discussed in a brainstorming session with a risk analysis expert to identify:

- Technical drifts that can be perceived by the operator and the associated drifts/advents of the interaction;

- Potential operator responses to perceived technical drifts and the associated drifts/advents of the interaction;

- Potential risks for the operator in the event of such responses.

At the end of applying the second step to the "SFP situation" case study, two hazardous situations were identified as significant:

(i) Potential electrical or mechanical injuries:

(a) Technical drift: dysfunction of the "piece 01 distributor" can result in a "Piece 01 position" drift by being "other than" in the expected position (i.e. piece 01 is ejected and can be either on the ground or stuck somewhere in the SFP machine);

(b) Perception: a new sensorial interaction between piece 01 and the operator: "the operator sees piece 01 outside the process";

(c) Operator responses: the operator can try to extract the piece, leading to physical interaction with another machine component;

(d) Hazard: physical interactions with sharp edges can lead to cuts while physical interaction with electrical parts can lead to electrification.

Potential musculoskeletal disorder: (a) Technical drift: the dysfunction of the "Sled conveyor" leads to the degradation of "Moving the sled from the work zone to the exit" activity. The post condition of this "Sled's position" activity drifts by being "other than" in the expected position (i.e. the sled is not at the end of the conveyor of the "SFP machine");

(b) Perception: the message "Sled position" (i.e. information transmitted) of the sensorial interaction between the sled and the operator drifts by being "other than" in the expected position (i.e. the operator sees that the sled is not at the end of the conveyor).

(c) Operator response: "The operator grabs and moves the sled" potential zone of operating drift by being "other than" in the expected situation (i.e. the operator performs a motion different from normal to grab and move the sled).

(d) Hazard: this operator response can lead to more effort and bad posture during the interaction between the output sled and the operator.

\section{Discussions and Conclusion}

\subsection{Discussion on the results of application to the case study}

The application of the WSHM method to the "SFP situation" case study proved the feasibility of the first and second steps but also the need to improve it.

It allowed improving the modeling part in the first step and of the identification of interactions drifts/advents part in the second part.

During the application of the WSHM method to the case study, the "potential hazard" analysis showed it can be used not only to identify potential injuries to the machine operator, but also hazardous situations for the operator's health (i.e. bad posture, excessive effort, etc.).

\subsection{Defining a working situation health's indicators}

The result of the second step will be used in the last step of the WSHM method to define a working situation health's indicator to allow monitoring the working situation studied. This indicator will be based on indicators of degradation of the machine's components, interactions and/or activities.

\subsection{Conclusion}

The application of the WSHM method to a case study allowed improving the method. It also provided feedback on its applicability.

The main negative feedback on the method was that its use required more time than the previous risk analysis method used by the members of the workgroup.

The positive negative feedback on the method confirmed the original contribution of the WSHM: 
- The use of a model and documents in all the steps allowed good re-usability of the results;

- The fact that the method relies on both theoretical expertise and user experiences led to finding more hazardous operator responses than by using user experience alone (especially in the part dedicated to "operation perception capabilities" and "operator responses";

- The use of a model in the first part also allowed integrating the method in design and not just in an already existing working situation.

Future work will take into account these feedbacks to continue improving the method. More case studies will be carried out in order to verify that the method is applicable to all work situations on automated assembly lines.

\section{References}

AIPL. 2021. 'https://aip-primeca.univ-lorraine.fr/espaceacademique/', Accessed march, 1st 2021.

Baybutt, Paul. 2015. 'A critique of the Hazard and Operability (HAZOP) study', Journal of Loss Prevention in the Process Industries, 33: 52-58.

Bouffaron, Fabien, Jean-Marc Dupont, Frédérique Mayer, and Gérard Morel. 2014. "Integrative construct for modelbased human-system integration: a case study." In 19th IFAC World Congress, IFAC'14.

Boy, Guy André. 2015. "On the complexity of situation awareness." In Proceedings 19th Triennial Congress of the IEA, 14.

Boyd, John. 1995. 'OODA loop', Center for Defense Information, Tech. Rep.

Brasseur, Grégory, Céline Ravallec, and Delphine Vaudoux. 2019. 'Le risque machine', Travail \& Sécurité: 12-25.

CE. 2006. "DIRECTIVE 2006/42/CE " In.

CE;. 2009. "DIRECTIVE 2009/104/CE " In.

Chauvin, Christine. 2010. 'Le facteur humain et la sécurité maritime', Revue Maritime: 14.

Cocheteux, Pierre. 2010. 'Contribution à la maintenance proactive par la formalisation du processus de pronostic des performances de systèmes industriels', Université Henri Poincaré-Nancy I.

Demasy, Séverine, Hugues Fièvre, Pascal Jacquetin, and Stéphanie De Flaugergues. 2020. 'Le risque machine, encore une réalité ?', Hygiène et Sécurité du travail: 7882.

Desroches, A. 2005. "Les invariants de l'analyse préliminaire des risques." In.: Qualita.

Duponnois, Romain, Pascal Lamy, Eric Levrat, and Ali Siadat. 2020. "Working situation reference model for risk assessment on automated assembly lines." In 30th European Safety and Reliability Conference and 15th Probabilitic Safety Assessment and Management Conference, ESREL 2020 PSAM 15.

Duponnois, Romain, Eric Levrat, Ali Siadat, and Pascal Lamy. 2019. "Vers le WSHM (Working Situation's Health Monitoring) pour la prévention des accidents du travail." In 16ème colloque national S-mart/AIP-PRIMECA.

Endsley, Mica R. 2017. 'From here to autonomy: lessons learned from human-automation research', Human Factors, 59: 5-27.

Endsley, Mica R, and DJ Garland. 2000. 'Theoretical underpinnings of situation awareness: A critical review', Situation awareness analysis and measurement, 1: 24.

Hoc, Jean-Michel. 2000. 'La relation homme-machine en situation dynamique', Revue d'Intelligence Artificielle, 14: 55-71.
Hollnagel, Erik. 2006. 'Achieving system safety by resilience engineering'.

IEC, NF EN. 2018. "NF EN IEC 60812 : 2018-Failure modes and effects analysis (FMEA and FMECA)." In.: AFNOR.

ISO. 2010. "ISO 12100 : Safety of machinery -- General principles for design -- Risk assessment and risk reduction." In $B S$ EN ISO, 12100-2.

ISO;. 2012. "ISO/TR 14121-2: Safety of Machinery-risk Assessment-Part 2: Practical Guidance and Examples of Methods." In.: ISO Geneva.

Kalgren, Patrick W, Carl S Byington, Michael J Roemer, and Matthew J Watson. 2006. "Defining PHM, a lexical evolution of maintenance and logistics." In 2006 IEEE autotestcon, 353-58. IEEE.

Lamy, Pascal, and Nellie Perrin. 2020. 'Approach to analyse hazardous situations tied to recurrent production dysfunctions, by observing the work situation', International Journal of Occupational Safety and Ergonomics: 1-9.

Larouzée, Justin, Franck Guarnieri, and Denis Besnard. 2014. 'Le modèle de l'erreur humaine de James Reason', MINES ParisTech.

Le Bot, Pierre. 2011. 'Suivre la prescription et prendre l'initiative pour être sûr: la résilience en situation', 29 et 30 novembre 2011: 95.

Léger, Aurélie. 2009. 'Contribution à la formalisation unifiée des connaissances fonctionnelles et organisationnelles d'un système industriel en vue d'une évaluation quantitative des risques et de l'impact des barrières envisagées', Université Henri Poincaré-Nancy I.

Lieber, Romain, and Gérard Morel. 2015. 'IMPROVING HUMAN-MACHINE INTERACTION REQUIREMENTS FOR MAINTENANCE ENABLING SYSTEMS SPECIFICATION', INSIGHT, 18: 14-16.

Modelio. 2021. 'https://www.modelio.org/', Accessed march, 1st 2021.

MORTUREUX, Yves. 2002. 'Analyse préliminaire de risques'.

OMG. 2019. 'SysML v. 1.6'.

Pariès, J. 2011. 'De l'obéissance à la résilience, le nouveau défi de la sécurité', Les entretiens du Risques 2011.

Pariès, Jean. 2015. "Rule-based vs managed safety : from compliance to resilience." In 8th International Conference Safety of Industrial Automated Systems. Königswinter, Germany.

Pariès, Jean, and John Wreathall. 2017. Resilience engineering in practice: a guidebook (CRC Press).

Polet, Philippe, Frédéric Vanderhaegen, and Patrick Millot. 2009. 'Human behaviour analysis of barrier deviations using a benefit-cost-deficit model', Advances in HumanComputer Interaction, 2009: 4.

Reason, James. 1990. Human error (Cambridge university press).

Reitz, A, E Levrat, JF Petin, A Noël, D Aigle, D Peiffert, and P Graff. 2012. 'Systematic approach for dysfunctional analysis in radiotherapy', Cancer radiotherapie: journal de la Societe francaise de radiotherapie oncologique, 16: 667-73.

ROYER, Michel. 2009. 'HAZOP: une méthode d'analyse des risques-Principe'.

Van Elslande, Pierre. 2000. 'L'erreur humaine dans les scénarios d'accident cause ou conséquence?', RechercheTransports-Sécurité, 66: 7-31.

Vanderhaegen, Frédéric, Stéphane Zieba, Simon Enjalbert, and Philippe Polet. 2011. 'A Benefit/Cost/Deficit (BCD) model for learning from human errors', Reliability Engineering \& System Safety, 96: 757-66. 